\title{
Bowel and bladder continence among children with spina bifida: a
} retrospective study

\author{
Michelle Campbell ${ }^{1}$, Susan Demetrides ${ }^{1}$, Elaine Stashinko ${ }^{1}$, Valerie Rogers ${ }^{5}$, \\ Keith Slifer², Yeggepan Lakshmanan ${ }^{4}$, T Andrew Zabel ${ }^{3}$ and Eric Levey*1
}

\begin{abstract}
Address: ${ }^{1}$ Neurology \& Developmental Medicine, Keelty Center for Spina Bifida, Kennedy Krieger Institute, North Broadway, Baltimore, Maryland, USA, ${ }^{2}$ Behavioral Psychology, Keelty Center for Spina Bifida, Kennedy Krieger Institute, North Broadway, Baltimore, Maryland, USA,

${ }^{3}$ Neuropsychology, Kennedy Krieger Institute, Keelty Center for Spina Bifida, Kennedy Krieger Institute, North Broadway, Baltimore, Maryland, USA, ${ }^{4}$ Urology, Johns Hopkins Hospital, Baltimore, Maryland, USA and ${ }^{5}$ School of Nursing, University of Maryland, Baltimore, Maryland, USA

Email: Eric Levey* - Levey@KennedyKrieger.org

* Corresponding author
\end{abstract}

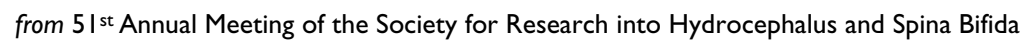

Heidelberg, Germany. 27-30 June 2007

Published: 20 December 2007

Cerebrospinal Fluid Research 2007, 4(SuppI I):SI8 doi:I0.II86/I743-8454-4-SI-SI8

This abstract is available from: http://www.cerebrospinalfluidresearch.com/content/4/SI/SI8

(C) 2007 Campbell et al; licensee BioMed Central Ltd.

\section{Background}

Spina bifida (SB) remains a common birth defect in the United States, affecting approximately one in three thousand live births. Bowel and bladder continence has a significant impact on quality of life in individuals with spina bifida. Objectives: To describe (1) the range of continence outcomes for children with spina bifida receiving usual care from an established multidisciplinary SB clinic and (2) the physiologic, medical, individual, family and environmental factors that contribute to bowel and bladder continence in children with SB.

\section{Materials and methods}

Records of patients evaluated during the last 3 years at a regional SB center were reviewed. Inclusion criteria included: age 5 through 18 years, SB diagnosis and no history of bladder or cloacal extrophy or sacral agenesis/caudal regression. Medical records of 96 eligible patients, from a total of 116 screened, were abstracted. Sample mean age was 11.5 years. Fifty-one (53\%) were males and 45 (47\%) were females. The majority (85\%) had myelomeningocele and $79 \%$ had hydrocephalus.

\section{Results}

The majority of children (76/95) utilized clean intermittent catherization (CIC) for bladder emptying. Of the remaining children, 9 were continent with spontaneous voiding, 5 used timed toileting, and 5 voided into a diaper. The vast majority of children using CIC reported some leaking $(73 \%)$. Most children who had urine leakage also had bowel incontinence (74\%). There was a positive relationship between having a recent urinary tract infection (UTI) and leaking between CIC/voids (Phi = $0.41, \mathrm{p}<0.01)$. Other treatments for urinary incontinence included anticholinergic medications (46\%), urologic surgery (31\%) and behavioral approaches. Bowel management included oral medications, suppositories, antegrade and retrograde enemas, and assisted evacuation. Bowel surgery was done in $29 \%$. The top barriers to adherence to toileting routines for the child were: initiation, anxiety, organization, and memory. For adults/caregivers barriers to adherence included lack of provision of positive reinforcement, lack of understanding of developmentally appropriate supervision, and lack of medication/ routine organization.

\section{Conclusion}

The majority of children with SB still have some bowel and bladder incontinence despite medical intervention. This research demonstrated the prevalence of incontinence in this population and formed the basis for our current prospective randomized controlled study to assess 
whether a behavioural intervention can improve compliance, decrease medical complications, and improve health-related quality of life in children with SB.

Publish with Bio Med Central and every scientist can read your work free of charge

"BioMed Central will be the most significant development for disseminating the results of biomedical research in our lifetime. " Sir Paul Nurse, Cancer Research UK

Your research papers will be:

- available free of charge to the entire biomedical community

- peer reviewed and published immediately upon acceptance

- cited in PubMed and archived on PubMed Central

- yours - you keep the copyright

Submit your manuscript here:

http://www.biomedcentral.com/info/publishing_adv.asp 